\title{
Homology Modeling of an Algal Membrane Protein, Heterosigma Akashiwo $\mathrm{Na}^{+}-$ATPase
}

\author{
Taeho Jo' ${ }^{1)}$, Mariko Shono ${ }^{2)}$, Masato Wada $^{3)}$, Sayaka Ito ${ }^{1)}$, \\ Junko Nomoto ${ }^{1)}$, and Yukichi Hara ${ }^{1) *}$
}

1) Biochemistry and Biophysics, Graduate School of Healthcare Sciences

Tokyo Medical and Dental University, Bunkyo-ku, Tokyo 113-8519, Japan

2) Tropical Agriculture Research Front, Japan International Research Center for Agricultural Sciences Maezato Kawarabaru, Ishigaki, Okinawa 907-0002, Japan

3) Apple Research Station, National Institute of Fruit Tree Science, National Agriculture and Food Research Organization, Shimokuriyagawa, Morioka, Iwate 020-0123, Japan

The three-dimensional structure of Heterosigma akashiwo $\mathrm{Na}^{+}$-ATPase (HANA) was predicted by means of homology modeling based on the crystal structure of the $\mathrm{K}^{+}-$bound form of shark $\mathrm{Na}^{+} / \mathrm{K}^{+}-\mathrm{ATPase}$ (PDB ID: 2ZXE). The overall structure of HANA appears to be similar to that of shark $\mathrm{Na}^{+} / \mathrm{K}^{+}-\mathrm{ATPase}$. Both contain three characteristic cytoplasmic domains, A, N and P, which are unique to P-type ATPases. HANA has a long TM7-8 junction as a large extracellular domain, in place of the $\beta$-subunit of shark $\mathrm{Na}^{+} / \mathrm{K}^{+}-\mathrm{ATPase}$. Two putative $\mathrm{K}^{+}-$binding sites in the transmembrane domain of HANA were identified by means of valence mapping based on the constructed structure. The presence of $\mathrm{K}^{+}$-binding sites and the reported ion requirements for ATPase activity and EP formation indicate that HANA may transport $\mathrm{K}^{+}$ions in the same manner as animal $\mathrm{Na}^{+} / \mathrm{K}^{+}-\mathrm{ATPases}$.

Key words : Heterosigma akashiwo $/$ marine alga $/ \mathrm{Na}^{+} / \mathrm{K}^{+}$-ATPase $/$homology modeling $/ \mathrm{K}^{+}$-binding sites

\section{Introduction}

Most living cells maintain a low intracellular concentration of $\mathrm{Na}^{+}$ions, despite the generally higher $\mathrm{Na}^{+}$ion concentration in the extracellular milieu. Plant cells have been believed to extrude intracellular $\mathrm{Na}^{+}$ions primarily through the combined action of a $\mathrm{Na}^{+} / \mathrm{H}^{+}-$ antiporter and $\mathrm{H}^{+}$-ATPase, rather than via a sodium pump. However, Heterosigma akashiwo, a wall-less unicellular marine alga, was found to contain $\mathrm{Na}^{+}-$ATPase on the plasma membrane ${ }^{1,2)}$. The ATPase activity is greatly stimulated in the presence of $100 \mathrm{mM}$ $\mathrm{NaCl}, 10 \mathrm{mM} \mathrm{KCl}$ and $5 \mathrm{mM} \mathrm{MgCl}_{2}$, and is inhibited by orthovanadate, a specific inhibitor of P-type ATPases. ATP-dependent $\mathrm{Na}^{+}$transport was also demonstrated

* Corresponding Author

Tel: $+81-3-5803-5364$

Fax: +81-3-5803-0161

E-mail: y.hara.mbch@tmd.ac.jp using reconstituted vesicles containing $H$. akashiwo plasma membrane ${ }^{3)}$. The ATPase formed phosphorylated enzyme intermediates of approximately $140-\mathrm{kDa}$ in the presence of $\mathrm{Na}^{+}$and $\mathrm{Mg}^{2+}$ ions ${ }^{1,2,4)}$. An antibody raised against pig kidney $\mathrm{Na}^{+} / \mathrm{K}^{+}-\mathrm{ATPase}$ reacted with the $140-\mathrm{kDa}$ polypeptides ${ }^{4}$. The full-length $\mathrm{cDNA}$ of

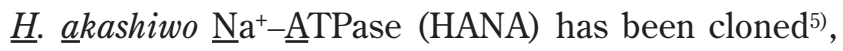
and the putative product shows about $40 \%$ identity with animal $\mathrm{Na}^{+} / \mathrm{K}^{+}$-ATPase $\alpha$-subunits and contains several conserved P-type ATPase sequences, including ATP binding site and phosphorylation site. Moreover, considerably higher identity ( $65 \%$ on average) was found between the 10 putative transmembrane domains of HANA and those of animal $\mathrm{Na}^{+} / \mathrm{K}^{+}-$ATPase $\alpha$-subunits. These data strongly suggest that HANA is a $\mathrm{Na}^{+}$and $\mathrm{K}^{+}$transporting P-type ATPase, and its reaction mechanism might be similar to that of $\mathrm{Na}^{+} / \mathrm{K}^{+}$-ATPases, though $\mathrm{K}^{+}$transport by HANA has not yet been demonstrated.

Recently, the X-ray crystal structure of $\mathrm{K}^{+}$-bound 
form of shark rectal gland $\mathrm{Na}^{+} / \mathrm{K}^{+}$-ATPase has been elucidated at 2.4- $\AA$ resolution ${ }^{6}$. We utilized this structure to predict the location of $\mathrm{K}^{+}$-binding sites in HANA by means of homology modeling. In this report, we discuss the putative $\mathrm{K}^{+}$-binding sites of HANA, and propose that HANA transports $\mathrm{K}^{+}$in the same manner as animal $\mathrm{Na}^{+} / \mathrm{K}^{+}-\mathrm{ATPases}$.

\section{Materials and Methods}

\subsection{Homology modeling of HANA}

The amino acid sequence of HANA (UniProt ID: Q9SXK5) was aligned with that of shark rectal gland $\mathrm{Na}^{+} / \mathrm{K}^{+}$-ATPase $\alpha 1$ (PDB ID: 2ZXE) by using a maximum matching program (Genetyx Co. Ltd., Tokyo). With the crystal structure of shark rectal gland $\mathrm{Na}^{+} / \mathrm{K}^{+}-\mathrm{ATPase}$ as a template, the 3D structure of HANA was generated by the modeling software MODELLER 9v77). Energy minimization was done with Swiss Protein Database Viewer ${ }^{8)}$. The calculated structure was evaluated by PROCHECK ${ }^{9)}$. PyMol (http://www.pymol.org) was used for visualizing chemical bonds and calculating the distances between atoms. The valence values for $\mathrm{K}^{+}$were calculated based on the equation $s=\left(R / R_{1}\right)^{-N}$, where $s$ is the bond valence, $R$ the cation-oxygen bond length, and $R_{1}$ and $\mathrm{N}$ are empirical parameters according to Brown and $\mathrm{Wu}^{10}$. The valence mapping was carried out at 0.1- $\AA$ intervals throughout the constructed model using VALE software, kindly provided by Di Cera ${ }^{11}$. Threshold valence for the calculation was set at 0.90 . To take water molecules into consideration, Fold-X ver.2.52 software (http://foldx.crg.es/) was used for predicting the positions of structural water molecules in protein structures.

\section{Results}

\subsection{Modeling of HANA}

Protein sequence alignment of HANA and shark $\mathrm{Na}^{+}, \mathrm{K}^{+}$-ATPase $\alpha$-subunit showed that both sequences contain $10 \mathrm{TMs}$ at similar positions, and the lengths of the TMs and loops TM2-3, TM3-4, TM5-6, TM6-7, TM8-9, and TM9-10 are essentially the same in the two sequences. But, HANA has a six-fold longer TM7-8 loop (290 aa) than shark $\mathrm{Na}^{+}, \mathrm{K}^{+}-$ATPase $\alpha-$ subunit (41 aa). Overall, HANA showed remarkable similarity to shark $\mathrm{Na}^{+} / \mathrm{K}^{+}-\mathrm{ATPase} \alpha 1$-subunit, with

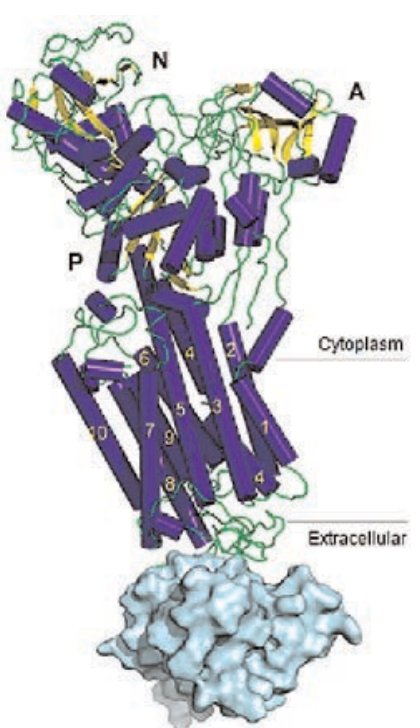

a)

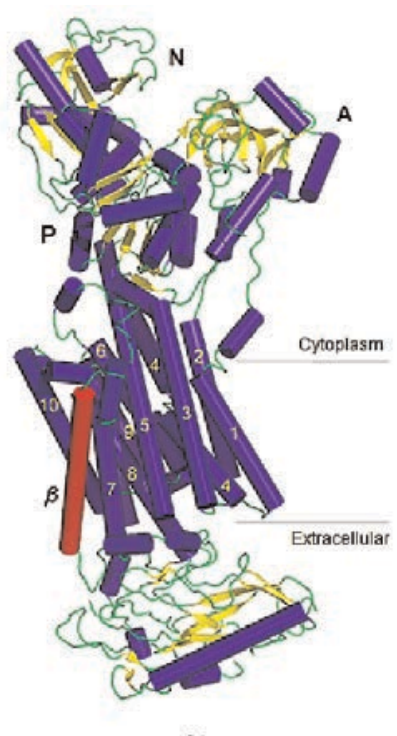

b)
Fig. 1 The $3 \mathrm{D}$ structures of HANA and $\mathrm{Na}^{+} / \mathrm{K}^{+}-\mathrm{ATPase}$. Cylinders and ribbons represent $\alpha$-helices and $\beta-$ strands, respectively. The numbers of transmembrane regions, and the $\mathrm{A}-, \mathrm{N}-$ and $\mathrm{P}-$ domains are indicated. a) Model of HANA generated by means of homology modeling. An amorphous mass on the extracellular side indicates a long loop of the TM7-8 region of HANA. b) Atomic structure of shark $\mathrm{Na}^{+} / \mathrm{K}^{+}-$ATPase (PDB ID: 2ZXE). $\beta$ indicates the $\beta$-subunit.

an identity of $55.0 \%$ and a homology of $79.7 \%$ at the amino acid level (Supplementary Figure). Taking advantage of this high homology, the 3D structure of HANA was constructed based on the crystal structure of the $\mathrm{K}^{+}$-bound form of shark $\mathrm{Na}^{+} / \mathrm{K}^{+}$-ATPase. A long loop of the TM7-8 region of HANA was shown as an amorphous mass on the extracellular side. Fig. 1 shows the predicted overall architecture of HANA, and the crystal structure of shark $\mathrm{Na}^{+} / \mathrm{K}^{+}-$ATPase. Both structures appear quite similar, having 10 transmembrane segments TM1-10, and three intracellular characteristic domains, i.e. A, N, and P. At the extracellular side, HANA has a longer TM7-8 loop region in place of the $\mathrm{Na}^{+} / \mathrm{K}^{+}-\mathrm{ATPase} \beta$-subunit. The predicted model of HANA was evaluated with the PROCHECK program, which showed that $86.8 \%$ of amino acid residues in the model reside in the most favored region and $10.7 \%$ in the additionally allowed region of the Ramachandran plot. The percentage of amino acid residues in the disallowed region was less than $1.2 \%$. The overall goodness factor, which represents the plausibility of covalent bond-angles and bond-distances of 

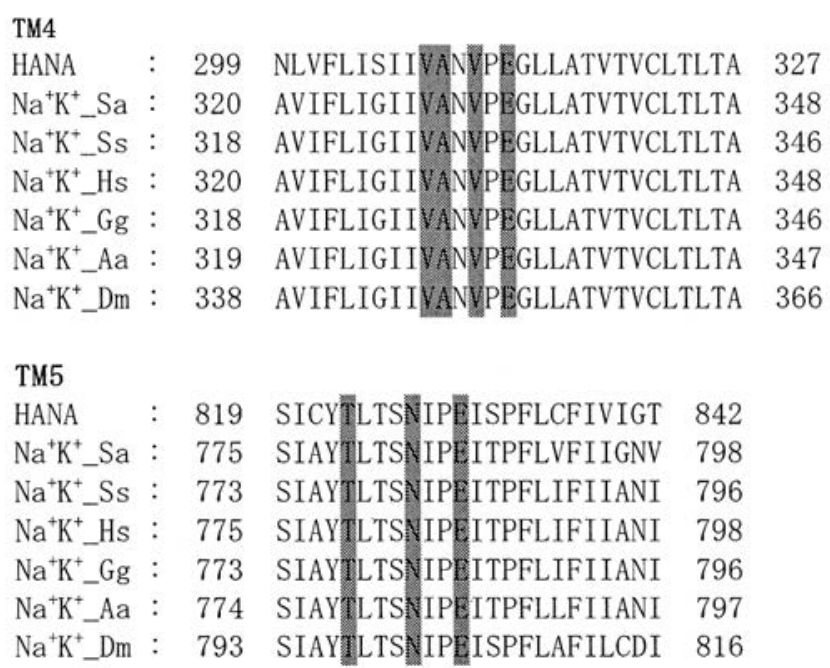

TM6

HANA : 846 LSTVLILGIDLLTDMVPAISMAY 868

$\mathrm{Na}^{+} \mathrm{K}_{-}^{+} \mathrm{Sa}: 802$ LGTVTILCIDLGTDMVPAISLAY 824

$\mathrm{Na}^{+} \mathrm{K}_{-}^{+} \mathrm{Ss}: 800$ LGTVTILCIDLGTDMVPAISLAY 822

$\mathrm{Na}^{+} \mathrm{K}^{+}{ }_{-} \mathrm{Hs}$ : 802 LGTVTILCIDLGTDMVPAISLAY 824

$\mathrm{Na}^{+} \mathrm{K}^{+}{ }_{-} \mathrm{Gg}: 800$ LGTCTILCIDLGTDMVPAISLAY 822

$\mathrm{Na}^{+} \mathrm{K}^{+} \_\mathrm{Aa}: 801 \quad$ LGTVTILCIDLGTDMVPAISLAY 823

$\mathrm{Na}^{+} \mathrm{K}^{+} \_\mathrm{Dm}$ : $820 \quad$ LGTVTILCIDLGTDMVPAISLAY 842

Fig. 2 Comparison of amino acid sequences in TM4, TM5 and TM6 among HANA and animal $\mathrm{Na}^{+} / \mathrm{K}^{+}-$ ATPases (Sa; Squalus acanthias, Ss; Sus scrofa, Hs; Homo sapiens, Gg; Gallus gallus, Aa; Anguilla anguilla, Dm; Drosophila melanogaster).

The residues directly contributing to $\mathrm{K}^{+}$-binding are shown on a gray background. Numbers flanking each sequence indicate the residue numbers at the start and end of the sequence.

the estimated structure, and which should exceed -0.5 for a reliable model ${ }^{7}$, was found to be -0.21 in the case of HANA.

\subsection{Identification of $\mathrm{K}^{+}$-binding sites}

Fig. 2 shows the alignments of amino acid sequences of TM4, 5 and 6 , which contribute to $\mathrm{K}^{+}$binding, ${ }^{6,12)}$, among shark, human, chicken, eel and Drosophila $\mathrm{Na}^{+} / \mathrm{K}^{+}-$ATPase $\alpha 1$-subunits and HANA. A comparison of the transmembrane sequences of HANA with the corresponding shark sequences revealed identities of $86.2,70.8$ and $82.6 \%$, in M4, M5 and M6, respectively, as shown in Table 1 . The amino acid residues directly contributing to $\mathrm{K}^{+}$binding in shark $\mathrm{Na}^{+} / \mathrm{K}^{+}-\mathrm{ATPase}{ }^{6)}$ are completely conserved in HANA, as shown in Fig. 2. We then attempted to predict the coordination geometry of the amino acid residues in the putative $\mathrm{K}^{+}$binding sites of HANA by using homol-
Table 1 Similarity and Identity of HANA versus Shark $\mathrm{Na}^{+} / \mathrm{K}^{+}-\mathrm{ATPase}$

\begin{tabular}{cccccc}
\hline & & \multicolumn{3}{c}{ HANA vs. Shark Na ${ }^{+} / \mathrm{K}^{+}$-ATPase } \\
\cline { 3 - 7 } region & residues & \multicolumn{2}{c}{ Similarity } & \multicolumn{2}{c}{ Identity } \\
\cline { 3 - 7 } & & residues & $\%$ & residues & $\%$ \\
\hline TM1 & 22 & 18 & 81.8 & 13 & 59.1 \\
TM2 & 20 & 19 & 95.0 & 13 & 65.0 \\
TM3 & 23 & 21 & 91.3 & 14 & 60.9 \\
TM4 & 29 & 28 & 96.6 & 26 & 86.2 \\
TM5 & 24 & 21 & 87.5 & 17 & 70.8 \\
TM6 & 23 & 21 & 91.3 & 19 & 82.6 \\
TM7 & 26 & 22 & 84.6 & 15 & 57.7 \\
TM8 & 22 & 18 & 81.8 & 13 & 59.1 \\
TM9 & 26 & 19 & 73.1 & 12 & 46.2 \\
TM10 & 16 & 13 & 81.3 & 8 & 50.0 \\
\hline Total & 231 & 200 & 86.6 & 149 & 64.5
\end{tabular}
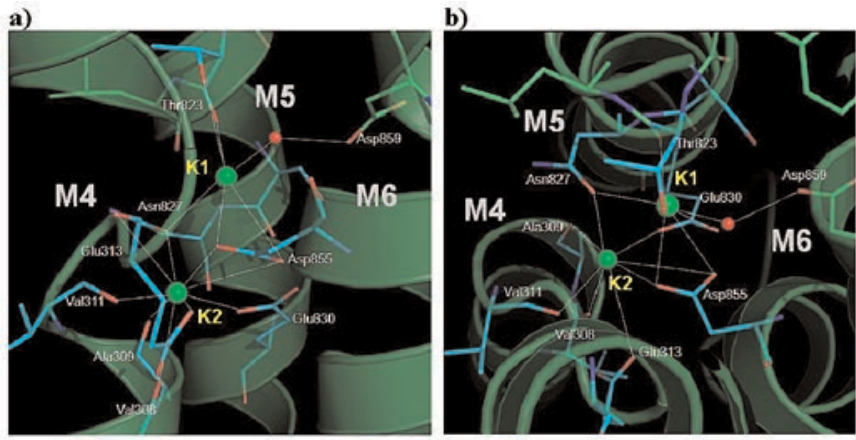

Fig. 3 Coordination geometry of $\mathrm{K}^{+}$-binding sites in HANA and $\mathrm{Na}^{+} / \mathrm{K}^{+}-\mathrm{ATPase}$. Green sphere represents $\mathrm{K}^{+}$ ion and red sphere oxygen atom. a) $\mathrm{K}^{+}$-binding sites of HANA viewed in parallel to the membrane. b) $\mathrm{K}^{+}$-binding sites of HANA viewed from the cytoplasmic side.

ogy modeling. As a water molecule is involved in $\mathrm{K}^{+}$ coordination in the case of shark $\mathrm{Na}^{+} / \mathrm{K}^{+}-\mathrm{ATPase}$, locations of structural water molecules on the structure of HANA were predicted, the locations of bound $\mathrm{K}^{+}$were determined by using valence mapping. Fig. 3 a, and b show the putative $\mathrm{K}^{+}-$binding sites of HANA from different angles. The predicted $\mathrm{K}^{+}$binding sites are similar to those of shark $\mathrm{Na}^{+} / \mathrm{K}^{+}-\mathrm{ATPase}$ (Fig. $3 \mathrm{a}$ and $\mathrm{b}^{6)}$ ). In HANA, the amino acid residues whose oxygen atoms lie within $4 \AA$-distance from the $\mathrm{K}^{+}$ions were Thr823, Asn827, Asp855 and Asp859 for site I , and Val308, Ala309, Val311, Glu313, Asn827, Glu830 and Asp855 for site II . There mostly correspond well with the residues involved in $\mathrm{K}^{+}$binding in HANA and shark $\mathrm{Na}^{+} / \mathrm{K}^{+}$-ATPase, except that Ser826, corresponding to Ser782 in shark $\mathrm{Na}^{+} / \mathrm{K}^{+}-\mathrm{ATPase}$, is placed quite far from $\mathrm{K}^{+}$-binding site I in the constructed model. 
Table 2 Coordinating oxygen atoms around bound $\mathrm{K}^{+}$ions within $4.0 \AA$-distance and valences.

\begin{tabular}{cccc}
\hline & \multicolumn{3}{c}{ HANA } \\
\cline { 2 - 4 } site & distance $(\AA)$ & valence for $\mathrm{K}^{+}$ \\
\hline & residue & $3.59(\mathrm{OG})$ & 0.016 \\
& Thr823 & 2.46 & 0.493 \\
& Thr823 & 3.31 & 0.033 \\
& Asn827 & 3.65 (OD) & 0.014 \\
& Asp855 & 3.00 (OD2) & 0.081 \\
Asp855 & 2.48 (water) & 0.458 \\
\hline Asp859 & & 1.094 \\
& sum & & \\
& & 3.11 & 0.058 \\
& Val308 & 2.71 & 0.204 \\
Ala309 & 2.63 & 0.268 \\
Val311 & 3.56 & 0.017 \\
Glu313 & 2.76 & 0.173 \\
Asn827 & 2.74 & 0.185 \\
Glu830 & 3.31 (OD1) & 0.033 \\
Asp855 & 2.75 (OD2) & 0.179 \\
\hline Asp855 & & 1.118 \\
& sum & &
\end{tabular}

Table 2 summarizes the distances between bound $\mathrm{K}^{+}$ ions and coordinating oxygen atoms and the valence values.

\section{Discussion}

In the previous paper, $\mathrm{Na}^{+}$transport was measured using proteoliposomes reconstituted with purified HANA. ATP was added extravesicularly and uptake of ${ }^{22} \mathrm{Na}^{+}$into the vesicles were measured. We examined a similar approach to detect ATP-dependent $\mathrm{K}^{+}$-transport in the same system, by measuring decrease in intravesicular $\mathrm{K}^{+}$concentration or increase in extravesicular $\mathrm{K}^{+}$concentration. However, this proved not to be feasible, because of the low $\mathrm{K}^{+}$transport activity of HANA. Therefore, we decided to search for putative $\mathrm{K}^{+}$binding sites by means of homology modeling.

The 3D structure of HANA was predicted by means of homology modeling. The results of an evaluation program and the obtained value of goodness factor $(-0.21)$ indicate that the constructed model of HANA is reliable.

The overall structure of HANA has considerable similarities with that of $\mathrm{Na}^{+} / \mathrm{K}^{+}-\mathrm{ATPase}$. Both have 10 transmembrane segments, TM1-10, and three characteristic cytoplasmic domains, A, N and P. Because the residues whose oxygen atoms contribute to $\mathrm{K}^{+}$-binding in $\mathrm{Na}^{+} / \mathrm{K}^{+}$-ATPase were completely conserved in HANA, we were able to estimate the positions of bound $\mathrm{K}^{+}$ions in HANA. In the predicted coordination geom-

\begin{tabular}{|c|c|c|}
\hline HANA & :923 & PPHILPG.GRGGF \\
\hline $\mathrm{Na}^{+} \mathrm{K}^{+} \_\mathrm{Sa}$ & 71 & DRVAPPGISHAPY \\
\hline $\mathrm{Na}^{+} \mathrm{K}^{+} \_\mathrm{Ss}$ & 70 & GLTQIPQ \\
\hline $\mathrm{Na}^{+} \mathrm{K}^{+} \_\mathrm{Hs}$ & & MIRPK \\
\hline $\mathrm{Ta}^{+} \mathrm{K}_{-}^{+} \mathrm{Gg}$ & & DR] \\
\hline${ }^{+} K^{+} A_{2}$ & & \\
\hline${ }^{+} \mathrm{K}^{+} \_\mathrm{Dn}$ & & LIG \\
\hline
\end{tabular}

Fig. 4 Comparison of amino acid sequences in TM7-8 loop of HANA with animal $\mathrm{Na}^{+} / \mathrm{K}^{+}$-ATPases $\beta$-subunits (Sa; Squalus acanthias, Ss; Sus scrofa, Hs; Homo sapiens, Gg; Gallus gallus, Aa; Anguilla anguilla, Dm; Drosophila melanogaster). Numbers flanking each sequence indicate the residue numbers at the start and end of the sequence.

etry of $\mathrm{K}^{+}$in HANA, the sums of valences were 1.094 and 1.118 for $\mathrm{K}^{+}$-binding sites I and $I$, respectively, as shown in Table 2. As the sums of valence values were close to 1.0 , the ideal value, $\mathrm{K}^{+}$ions should be bound with high affinity.

Homology modeling is a useful means to analyze molecular structure of membrane proteins because of the difficulty of crystallizing them. The structures of the $\mathrm{K}^{+}$binding sites of human $\mathrm{Na}^{+} / \mathrm{K}^{+}$-ATPase were predicted by means of homology modeling using the $\mathrm{Ca}^{2+}$ unbound form of $\mathrm{Ca}^{2+}-$ ATPase as template by Ogawa $^{13)}$. Our model was constructed based on the $\mathrm{K}^{+}$ bound form of shark $\mathrm{Na}^{+} / \mathrm{K}^{+}$-ATPase. As there is a very high homology between HANA and shark $\mathrm{Na}^{+} / \mathrm{K}^{+}$-ATPase, the obtained structure of $\mathrm{K}^{+}$binding sites should be reliable. The 3D model of $\mathrm{Na}^{+}$binding sites in HANA was not constructed, because of low homology in amino acid sequence between HANA and $\mathrm{Ca}^{2+}-$ ATPase (PDB ID: 1SU4).

$\mathrm{Na}^{+} / \mathrm{K}^{+}-\mathrm{ATPase} \beta$-subunit was reported to play a critical role in $\mathrm{K}^{+}$binding ${ }^{14,15}$. HANA lacks a $\beta$-subunit, but has a longer TM7-8 junction consisting of 290 amino acid residues, with a length similar to that of the $\mathrm{Na}^{+} / \mathrm{K}^{+}-$ATPase $\beta$-subunit. This loop contains ProGly-Leu (PGL), which is present in most $\beta$-subunits (Fig. 4). The PGL sequence in the $\beta$-subunit is located in the region involved in interaction with the $\alpha$-subunit ${ }^{6}$. Taking account of the extracellular localization of the TM7-8 junction, this junction might play a role equivalent to that of the $\mathrm{Na}^{+} / \mathrm{K}^{+}$-ATPase $\beta$-subunit.

HANA is faced with $450 \mathrm{mM} \mathrm{Na}^{+}$of seawater as well 
as shark rectal gland $\mathrm{Na}^{+} / \mathrm{K}^{+}-\mathrm{ATPase}$. The $\mathrm{Na}^{+}$/ $\mathrm{K}^{+}$-ATPase in marine environment was reported to have more positive amino acids in extracellular $\mathrm{Na}^{+}$ exit pathway, to reduce its sensitivity to external $\mathrm{Na}^{+}$ ions ${ }^{16)}$. Gly319 on TM3-4 loop in Loligo $\mathrm{Na}^{+} / \mathrm{K}^{+}-$ ATPase, conserved among the $\mathrm{Na}$ pumps of marine animals and one of the important residues for the high $\mathrm{Na}^{+}$adaptation. The Gly319 was also conserved as Gly293 in HANA and as Gly314 in shark $\mathrm{Na}^{+} / \mathrm{K}^{+}-$ ATPase.

It was reported that HANA was highly activated in the presence of both $\mathrm{Na}^{+}$and $\mathrm{K}^{+}$, and the steady-state level of phosphoenzyme was high in the presence of $\mathrm{Na}^{+}$, but very low in the presence of $\mathrm{K}^{+2}$. These characteristics resemble those of $\mathrm{Na}^{+} / \mathrm{K}^{+}-\mathrm{ATPase}$, so HANA might transport $\mathrm{K}^{+}$ions in the same way as animal $\mathrm{Na}^{+} / \mathrm{K}^{+}$-ATPases, though $\mathrm{K}^{+}$transport has not yet be demonstrated.

These kinetic and structural features of putative $\mathrm{K}^{+}$ binding in HANA strongly indicate that HANA transports $\mathrm{K}^{+}$as well as $\mathrm{Na}^{+}$, and that its mechanism of action is similar to that of $\mathrm{Na}^{+} / \mathrm{K}^{+}-\mathrm{ATPase}$ of animal cells.

$\mathrm{Na}^{+} / \mathrm{K}^{+}-$ATPases had long been believed to be present exclusively in animal cells. In 1995, however, cells of marine alga $H$. akashiwo were found by us to exhibit $\mathrm{Na}^{+} / \mathrm{K}^{+}$-ATPase-like activity ${ }^{2)}$, and lately aquatic fungus Blastocladiella emersonii was found to contain $\mathrm{Na}^{+} / \mathrm{K}^{+}-$ATPase-like activity by Flavio et al. ${ }^{17)}$ Moreover, the genes encoding animal $\mathrm{Na}^{+} / \mathrm{K}^{+}$-ATPase $\alpha$-subunit like molecules have been cloned from many organisms, containing alga, fungus and even archaebacteria ${ }^{18)}$. Then, an ancestral molecule of $\mathrm{Na}^{+} / \mathrm{K}^{+}$- ATPase may have emerged an early stage of evolution, and the possibility should be considered that molecules with $\mathrm{Na}^{+} / \mathrm{K}^{+}$-ATPase-like activity might also be present in plants as well as animal kingdom.

\section{Acknowledgements}

We are grateful for Prof. E. Di Cera, Washington University, for kindly providing the valence-mapping program, VALE.

\section{References}

1) Wada M, Satoh S, Kasamo K, Fujii T : Plant Cell Physiol., 30, 923-928 (1989)

2) Shono M, Wada M, Fujii T : Plant Physiol., 108, 1615-1621 (1995)

3) Shono M, Hara Y, Wada M, Fujii T : Plant Cell Physiol., 37, 385-388 (1996)

4) Wada M, Urayama O, Satoh S, Hara Y, Ikawa Y, Fujii T : FEBS Lett., 309, 272-274 (1992)

5) Shono M, Wada M, Hara Y, Fujii T : Biochim. Biophys. Acta, 151 1, 193-199 (2001)

6) Shinoda $\mathrm{T}$, Ogawa H, Cornelius F, Toyoshima C : Nature, 459, 446-451 (2009)

7) Sali A, Blundell TL: J. Mol. Biol., 234, 779-815 (1993)

8) Guex N, Peitsch MC : Electrophoresis, 18 2714 (1997)

9) Laskowski RA, MacArthur MW, Moss DS, Thornton JM : J. Appl. Cryst. 26, 283-291 (1993)

10) Brown ID, Wu KK : Acta Cryst., B32, 1957-1959 (1976)

11) Nayal M, Di Cera E : Proc. Natl. Acad. Sci. USA., 91, 817821(1994)

12) Morth JP, Pedersen BP, Toustrup-Jensen MS, Sorensen TL-M, Petersen J, Andersen JP, Vilsen B, Nissen P : Nature, 450, 1043-1050 (2007)

13) Ogawa H, Toyoshima C : Proc. Natl. Acad. Sci. USA., 99, 15977-15982 (2002)

14) Lutsenko S, Kaplan JH : Biochemistry, 32, 6737-6743 (1993)

15) Shainskaya A, Karlish SJD : J. Biol. Chem., 271, 1030910316 (1996)

16) Colina C, Rosenthal JJC, DeGiorgis JA, Srikumar D, Iruku N, Holmgren M : Nat. Struct. Mol. Biol., 14, 427431 (2007)

17) Flavio SJ, Souza D, Gomes SL : Biochim Biophys. Acta., 1383, 183-187 (1998)

18) Benito B, Rodriguez-Navarro A : Plant J., 36, 382-389 (2003)

(Received 19 January 2010; Accepted 2 February 2010) 


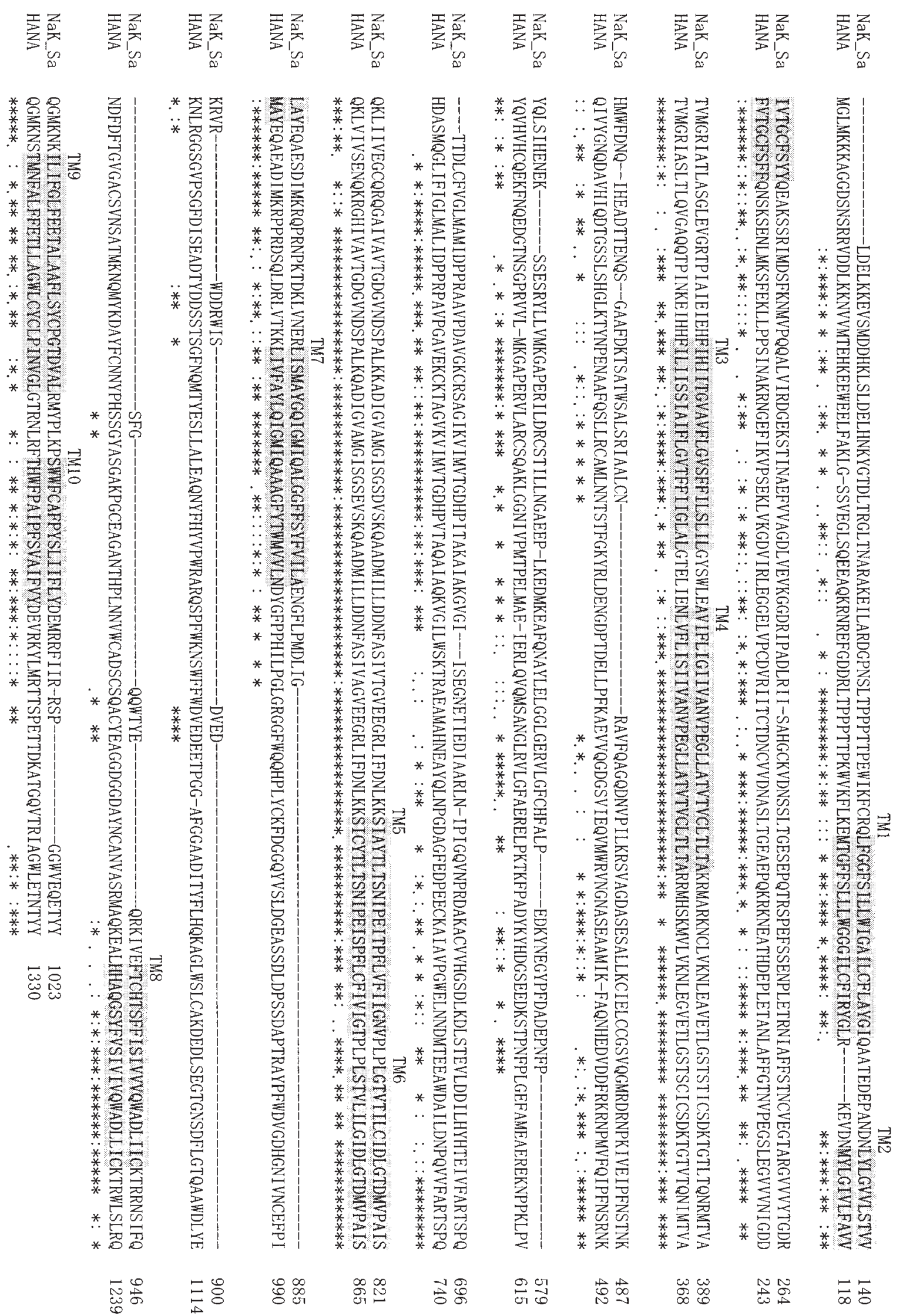

SupplementaryFigure Alignment of amino acid sequences of HANA (Q9SXK5) and the shark $\mathrm{Na}^{+} / \mathrm{K}^{+}-\mathrm{ATP} a \mathrm{se} \alpha 1$-subunit (2ZXE). Boxes indicate transmembrane regions.

Asterisks indicate identical amino acids, and colons and periods indicate highly and weakly similar amino acids, respectively. 